\title{
Variation in orosensation and liking of sampled foods with thermal tasting phenotype
}

\author{
Gary J. Pickering ${ }^{1,2,3,4,5^{*}}$, Sarah Lucas $^{2}$ and Nicole J. Gaudette
}

\begin{abstract}
Background: Flavour is a key driver of liking, purchase behaviour and consumption of food and beverages. Determining how individuals differ in their perception of flavour is important to fully understanding dietary choices and habitual diet-related health outcomes. Thermal tasting - the capacity to experience a phantom taste when small areas of the tongue are rapidly heated or cooled_associates with greater orosensory acuity for tastants in aqueous solutions. This study sought to extend this finding and establish whether thermal-taster status also associates with the perceived intensities of oral sensations elicited by sampled food. Twenty-five thermal tasters (TTs) and 19 thermal non-tasters (TnTs) scored liking (generalized degree of liking scale) and the intensity (generalized visual analogue scale) of the dominant orosensations elicited by 20 food and beverage items in duplicate using a randomized complete block design.

Results: Multiple analysis of variance (MANOVA) showed that overall, TTs rated the intensity of orosensory food groups higher than did TnTs, although this was significant only for foods that were predominantly bitter-eliciting (ANOVA). Overall liking scores approached significance (MANOVA) but differed between TTs and TnTs only for the grainy orosensory food grouping (ANOVA).

Conclusions: These findings are discussed in the context of diet-related health outcomes and directions for further research concerned with taste phenotypes, flavour perception and consumption behaviours.

Keywords: Taste phenotype, Nutrition, Flavour, Health, Food preferences, Taste genetics

Abbreviations: TTs, Thermal tasters; TnTs, Thermal non-tasters; TTS, Thermal taster status; ANOVA, Analysis of variance; gVAS, Generalized visual analogue scale; gLMS, Generalized labeled magnitude scale; gDOL, Generalized degree of liking
\end{abstract}

\section{Background}

Other than price and availability, the flavour of food and beverages tends to be the strongest predictor of their consumption and consequently a range of both health and nutritional outcomes [1-3]. Differences between individuals in their perception of orosensory (taste and chemesthetic) stimuli can influence habitual food intake and thereby risk of habitual diet-related disease [2]. For instance, individuals who sense the textural properties of

\footnotetext{
* Correspondence: gpickering@brocku.ca

${ }^{1}$ Department of Biological Sciences, Brock University, St. Catharines, Ontario L2S 3A1, Canada

²Department of Psychology, Brock University, St. Catharines, Ontario L2S 3A1, Canada

Full list of author information is available at the end of the article
}

fats or the sweetness of sugars less intensely may regularly consume more of each, thus potentially leading to excessive calorie intake and related disease states. In addition, food producers are interested in better understanding how consumers differ in perception of the flavour elicited by their products, particularly with respect to opportunities for product optimization and identifying new market segments [4].

A major source of individual differences in orosensation is genetic variation $[5,6]$. Thermal tasting is a taste phenotype with a likely genetic basis first noted by the Green lab in 2000 [7]; however, there have only been sporadic reports appearing in the literature since then. Thermal tasters (TTs) perceive a phantom taste when small 
sections of the tongue are cooled or heated [7-9]. The specific sensations elicited include sourness, sweetness, saltiness, bitterness and metallic, and vary with the area stimulated and the temperature regime used (i.e. heating or cooling). Some evidence from Trpm5 knockout mice suggests that TRPM5 (a TRP superfamily cation channel involved in the transduction of bitter, sweet and umami tastes) may play a role in thermal taste [10]. Of particular interest is the association between thermal taste status and perception of food and food-relevant stimuli.

In addition to experiencing a phantom sensation on lingual thermal stimulation, TTs also tend to rate the basic tastes and most chemesthetic sensations more intense than thermal non-tasters (TnTs) in aqueous solutions $[8,9,11,12]$. With respect to orosensory detection thresholds, Yang et al. [9] recently assessed whether thresholds varied with thermal-taster status (TTS) for sucrose, sodium chloride, caffeine and two trigeminal stimuli. Only one difference was found: the detection threshold for sucrose was lower for TTs than for TnTs. Pickering and Kvas [13] examined difference thresholds for sucrose, tartaric acid and quinine in white wine and found the thresholds for sucrose and tartaric acid were 33 and $68 \%$ lower for TTs, respectively, although this was only significant for tartaric acid. Extending this finding, TTs rated the dominant orosensations elicited by wine [14] and beer [15] more intensely than TnTs. Further research is needed to directly address whether the greater orosensory acuity, or consumption behaviours, suggested by TTs extends to sampled foods. However, Bajec and Pickering [16] found that self-reported liking of a large range of food items varied with TTS. Given the suggestion that reported liking may be a more accurate proxy for consumption than many traditional dietary intake measures [2], this has led to speculation that TTS may link to food and beverage consumption and nutritional and/or habitual diet-related health outcomes.

The main aim of this study was to investigate whether TTS associates with the intensity of oral sensations elicited by sampled common food products. Given the results to date in simple aqueous solutions, our hypothesis was that TTs would experience the dominant orosensations more intensely. Obesogenic foods were included amongst the specific products assessed. Secondary objectives were to (1) examine whether postulated differences between thermal taster groups would extend to liking of the food items and (2) further elucidate the association between self-reported and sampled liking.

\section{Methods}

\section{Participants}

Eighty-six participants were initially recruited from the Niagara Region through online listings and personal invitations, and comprised of student, staff and faculty members at Brock University. Participants attended three sessions in total, each lasting approximately $1 \mathrm{~h}$. An incentive to participate consisted of entry into a gift card draw, and eligible students received research participation credit to fulfil course requirements. All of the recruitment, screening and data collection procedures were cleared by the Brock University Research Ethics Board (REB File 10-193). Forty-two participants were excluded from the study; 13 were non-classifiable for TTS, 27 failed to complete all necessary sessions, and two participants were excluded based on age ( $>45$ years). Of the 44 participants that completed all sessions, 25 were thermal tasters (10 males) and 19 thermal non-tasters (11 males), aged $18-44$ years $(M=24.6$ years, $S D=5.9)$. Thirty-seven participants were Caucasian, and seven were non-Caucasian.

\section{Training and thermal taster status classification}

All training and data collection took place in the controlled Sensory Evaluation Laboratory at Brock University. For all sessions, participants were instructed not to eat or drink anything in the hour prior to attending. A brief questionnaire on demographic and health information was completed at the start of the study.

\section{Scale acclimation}

Participants were trained on the use of the generalized visual analogue scale (gVAS) to score sensation intensity. The scale is anchored with "no sensation" at the bottom end $(0 \mathrm{~mm})$ and "strongest experienced sensation of any kind" at the top end $(100 \mathrm{~mm})$, with three unlabeled and equidistant horizontal lines breaking up the scale into quadrants at 25, 50 and $75 \mathrm{~mm}$, respectively. Participants received both written and verbal instruction on how to use the gVAS scale appropriately. In order to familiarize participants with the scale and its correct use, they rated the intensity of five remembered sensations on paper copies (pain from biting your tongue, brightness of the sun when staring directly at it, sweetness of cotton candy, touch sensation of a pill on your tongue, and burning sensation from eating a whole hot pepper). The approach of Bajec and Pickering [8] was used to also train participants on correct use of the generalized labeled magnitude scale (gLMS) scale, which was used to collect responses to thermal elicitation later in the session. In addition to receiving written and verbal instruction on how to use the scale, participants also rated the intensity of five remembered sensations, as above.

Training with the generalized degree of liking (gDOL) scale [17] was also provided; this scale was used for self-rating listed food items in this session and liking of sampled foods in the subsequent sessions. The gDOL scale uses "strongest disliking of any kind" as an anchor at the bottom end and "strongest liking of any kind" as an anchor at the top end. Between these two extremes, "dislike" and 
"like" labels mark the regions of dislike and like and a line labeled "neutral" intersects the scale at the midpoint. Participants received both written and verbal instruction on how to appropriately use the gDOL scale. They were instructed to think of their strongest disliking and liking of any kind. These experiences were to be used as their anchor items and kept consistent throughout the study. To help familiarize participants with the scale, they rated their liking of various experiences, activities and food items (including those they were to receive in the sampled food sessions). Participants also received training on the use of Compusense $^{\text {tum }} 5.2$ (Compusense Inc., Guelph, ON), the computer program used to collect responses to sampled foods.

\section{Identification of tastants}

Participants were provided with samples of prototypical tastants, primarily to assist them with later identification of possible sensations elicited during the thermal-taste elicitation procedure. Aqueous solutions (Millipore RiOs $16 \mathrm{Re}-$ verse Osmosis System water, MA, USA) representing sweet (sucrose 85.58 g/L; Sigma-Aldrich, MO, USA), sour (citric acid $0.64 \mathrm{~g} / \mathrm{L}$; Fisher Scientific, NY, USA), bitter (quinine monohyrdochloride dehydrate $0.022 \mathrm{~g} / \mathrm{L}$; SAFC Supply Solutions, MO, USA), umami (L-glutamic acid monosodium salt hydrate $21.14 \mathrm{~g} / \mathrm{L}$; Sigma-Aldrich, MO, USA) and salty (sodium chloride $10.5 \mathrm{~g} / \mathrm{L}$; Caledon Laboratories Ltd, ON, Canada) were presented in random order in tastelabeled, clear ISO glasses at room temperature. Participants were instructed to take the entire $20-\mathrm{mL}$ sample in their mouth, swirl for $5 \mathrm{~s}$ and expectorate. Following a 10-s wait, participants rated the intensity of the sensation on individual gVAS scales. Between each sample, a minimum 1-min break was implemented during which participants were required to rinse with Brita ${ }^{\text {Tw }}$-filtered water and expectorate. A questionnaire was administered as an inter-stimulus rest exercise, and then the same samples labeled with random three-digit codes were presented in a re-randomized order. Participants were asked to identify and rate the intensity of each unknown sensation ('sweet', 'bitter,' 'sour,' 'salty' or 'umami') using individual gVAS scales. All participants correctly identified the tastants on the first attempt.

\section{Thermal-taster status determination}

A thermal eliciting device (TED) was built by the Brock University Electronics and Machine Shops, according to the specifications of earlier models $[7,8]$. TED is a thermode consisting of a $64-\mathrm{mm}^{2}$ computer-controlled Peltier device with a thermocouple feedback attached to a toothbrush sized water-circulated heat sink. The thermode is covered with fresh Saran wrap ${ }^{\text {max }}$ (SC Johnson, WI, USA) prior to contact with each participant, for hygienic purposes. The method for eliciting taste responses using TED consists of a formal regime of heating and cooling small areas of a participant's tongue, and was conducted approximately $15 \mathrm{~min}$ after the identification of tastants exercise described above. We followed the exact procedure of Bajec and Pickering [8].

On conclusion of the first heating and cooling cycles, participants completed a short questionnaire as an interstimulus break, before the same heating and cooling cycles were repeated again in a re-randomized order. No mouth rinses were used between trials/cycles. All intensity responses were collected on seven individual gLMS scales (heat, cool, sweet, salty, sour, bitter, others). Providing participants with scales that encompass the range of possible taste qualities they may experience allows for any sensation(s) elicited on thermal stimulation to be captured accurately and increases the likelihood of correctly identifying thermal tasters. Heat and cool were included to protect against dumping effects during the heating and cooling cycles, respectively. In addition to guidelines on how to correctly use the gLMS with respect to its anchor terms, participants were instructed to '...rate the intensity of sensations you experience upon cooling/heating of your tongue by indicating where it lies on a scale of all possible sensations'.

Participants were categorized as thermal tasters (TTs) when they rated the same sensation (excluding heat or cool) as above 'weak' for both replicates of the same temperature trial and at the same tongue location. Participants were classified as thermal non-tasters (TnTs) when no oral sensation other than temperature was detected on any part of the tongue, for any trial. Participants who did not meet either of the above criteria were categorized as non-classifiable and excluded from the study. These classification criteria have previously been employed by Green and George [11], Bajec and Pickering [8] and Bajec et al. [12]. The distribution of the intensity scores for the main prototypical tastes is given in Table 1. Figure 1 shows the taste qualities (\%) experienced by thermal tasters after application of the TED; the proportions are similar to those reported by Pickering and Klodnicki [18]. The proportion of participants classified as TTs in this study was $44 \%$, which is within the range found in other reports (27 \% [9], 31 \% [Thibodeau M, Bajec MR, Pickering GJ: Orosensory responsiveness, thermal tasting and alcohol behavior, Submitted], 50 \% [11]).

Table 1 Average intensity scores reported for main prototypical tastes on lingual thermal stimulation across all locations and temperature regimes \pm standard error of mean

\begin{tabular}{lllll}
\hline & & \multicolumn{3}{l}{ Thermal tasting status } \\
\cline { 3 - 5 } & Overall & Tasters & Non-tasters & Non-classifiable \\
\hline Sweet & $0.93 \pm 0.15$ & $1.65 \pm 0.29$ & $0.00 \pm 0.00$ & $0.60 \pm 0.15$ \\
Salty & $0.98 \pm 0.14$ & $1.78 \pm 0.26$ & $0.00 \pm 0.00$ & $0.54 \pm 0.18$ \\
Sour & $1.01 \pm 0.19$ & $2.02 \pm 0.38$ & $0.00 \pm 0.00$ & $0.20 \pm 0.07$ \\
Bitter & $1.55 \pm 0.22$ & $2.88 \pm 0.41$ & $0.00 \pm 0.00$ & $0.75 \pm 0.31$ \\
\hline
\end{tabular}




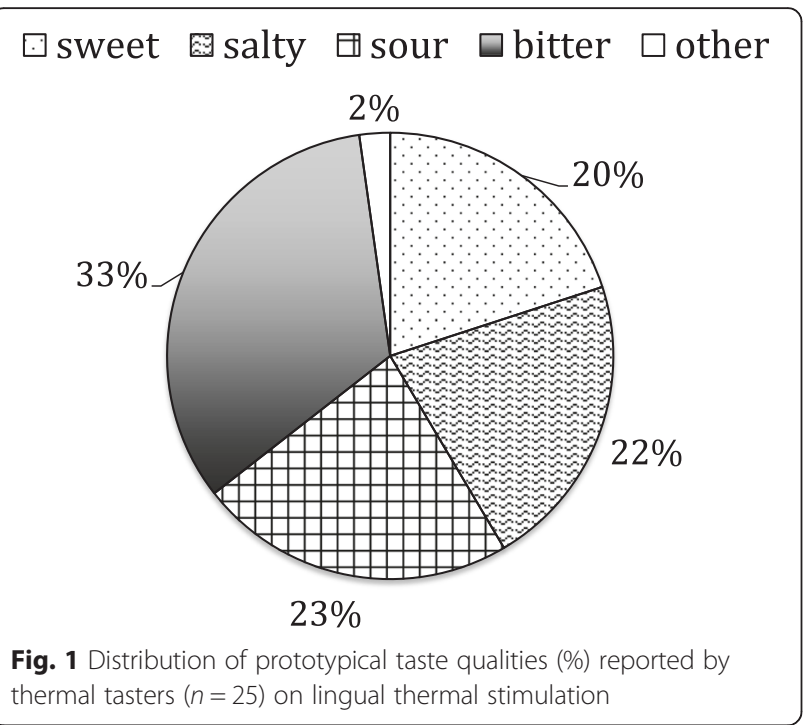

\section{Evaluation of sampled foods}

After extensive bench testing, 20 food and beverage products were selected to represent a wide range of commercially available everyday foods that encompass a range of orosensations. These included vegetables, milk products, salty snacks, sweet treats and textured foods (Table 2). To control consistency, items were purchased from the same grocery stores (Zehr's Markets and Sobey's) and evaluated quickly after purchase. Small portions of solid and liquid samples were served on plastic trays and in solo cups, respectively. All food samples were divided into serving portions up to $2 \mathrm{~h}$ before evaluation and were labeled with random threedigit codes. Participants who were successfully classified as TTs or TnTs in the initial session were invited to take part in the food evaluation portion of this study (sessions 2 and 3). Evaluation took place in individual booths within the controlled Sensory Evaluation Laboratory at Brock University, and participants were instructed not to eat or drink anything during the hour prior to the session.

\section{Experimental design}

A fully randomized block design was employed over two sessions to collect responses to the sampled food items. Prior to the start of each session, participants were required to rinse and expectorate with solutions representing the prototypical tastes using the tastants and concentrations from session 1 above. Individual food items were then presented monadically in a completely randomized order. Participants consumed each item and rated liking and intensity of oral sensations using computerized versions of the gDOL and gVAS, respectively. For each food product, the gVAS scales were presented on separate screens from the gDOL scale. Participants operated a mouse to click and/or re-click at any location along the scales to register liking and intensity scores. Each item was rated for intensity of the orosensations it most strongly elicited; these sensations were derived from the literature and bench tasting (Table 2). After each food item was assessed, a 1-min, 45-s break was mandated, during which participants were required to rinse with Brita $^{\text {Im }}$-filtered water and expectorate. This session was repeated a second time to generate duplicate ratings from each participant.

\section{Data treatment and analysis}

Statistical analysis was performed using XLSTAT version 2011.1.01 for Windows (Addinsoft, USA). For intensity responses, participant ratings were averaged across the duplicate data for each sensation and food. Two-way analysis of variance (ANOVAs) were then used to examine the mains effects of TTS and gender and their interaction on sensation intensity. A multiple ANOVA (MANOVA) followed by one-way ANOVAs were then used to examine the effect of TTS on sensation intensities elicited by foods collapsed into discrete orosensory groups. Orosensory groups were created through the identification and grouping of sub-sets of foods that shared a predominant taste, texture or chemesthetic quality, using the approach of [16]. The groups were populated by first pooling and then averaging the data of all participants to obtain mean values for each sensation and food. The data was then examined for natural beaks in the intensity ratings; categories and corresponding cut-off values are given in Table 3.

For each participant, the overall liking score was averaged across both replicates. Two-way ANOVAs were then used to examine the mains effects of TTS and gender and their interaction on liking. A MANOVA followed by one-way ANOVAs were then used to examine the effect of TTS on liking of food categories collapsed into the discrete orosensory groups determined above. Finally, food category groups were also formed (sweet treats, salty snacks, vegetables, milk products and textured foods) and assessed using one-way ANOVA. Examination of the association between self-rated liking of listed food items and liking of sampled items was done using Pearson's correlation. Alpha was set at 0.05 for all analyses.

\section{Results \\ Orosensations}

An initial investigation to assess whether the gVAS scales were being interpreted and used as intended was conducted. Average creaminess ratings for milk/ cream items showed the expected trend of increasing with fat content, with the overall analysis showing significant differences between products $(F(4,125)=$ 14.7, $p<0.0001)$. Similarly, dark chocolate was rated 
Table 2 Food and beverage items used in study, including preparation/serving protocols and oral sensations assessed

\begin{tabular}{|c|c|c|c|c|c|}
\hline Food groups & $\begin{array}{l}\text { Food or beverage } \\
\text { product }\end{array}$ & Brand and name & Serving size & Preparation & Oral sensations assessed \\
\hline \multirow[t]{4}{*}{ Vegetables } & Asparagus & $\begin{array}{l}\text { Marque Europe's Best Brand: } \\
\text { Asparagus spears }\end{array}$ & $\begin{array}{l}1 \text { tip } \\
\mathrm{v}(\sim 2.0 \mathrm{~g})\end{array}$ & \multirow{4}{*}{$\begin{array}{l}\text { Stored in freezer. Placed in refrigerator } \\
\text { to thaw up to } 24 \mathrm{~h} \text { before session. } \\
\text { Served directly from refrigerator }\end{array}$} & \multirow[t]{4}{*}{$\begin{array}{l}\text { Sweetness } \\
\text { Bitterness }\end{array}$} \\
\hline & Broccoli & $\begin{array}{l}\text { President's Choice: } \\
\text { Broccoli florets }\end{array}$ & $\begin{array}{l}1 \text { floret } \\
(\sim 2.0 \mathrm{~g})\end{array}$ & & \\
\hline & Brussels sprout & $\begin{array}{l}\text { President's Choice: } \\
\text { Baby brussels sprout }\end{array}$ & $\begin{array}{l}1 \text { sprout } \\
(\sim 5.0 \mathrm{~g})\end{array}$ & & \\
\hline & Sweet peas & $\begin{array}{l}\text { President's Choice: } \\
\text { Small sweet peas }\end{array}$ & $\begin{array}{l}8 \text { peas } \\
(\sim 1.5 \mathrm{~g})\end{array}$ & & \\
\hline \multirow[t]{5}{*}{ Milk products } & Skim milk & $\begin{array}{l}\text { Neilson Dairy: } \\
<0.5 \% \text { milk }\end{array}$ & $10 \mathrm{~mL}$ & \multirow[t]{7}{*}{$\begin{array}{l}\text { Stored in and served directly from } \\
\text { refrigerator }\end{array}$} & \multirow[t]{5}{*}{$\begin{array}{l}\text { Sweetness } \\
\text { Creaminess }\end{array}$} \\
\hline & Low-fat milk & $\begin{array}{l}\text { Neilson Dairy: } \\
1 \% \text { milk }\end{array}$ & $10 \mathrm{~mL}$ & & \\
\hline & Reduced-fat milk & $\begin{array}{l}\text { Neilson Dairy: } \\
2 \% \text { milk }\end{array}$ & $10 \mathrm{~mL}$ & & \\
\hline & Whole milk & $\begin{array}{l}\text { Neilson Dairy: } \\
3.25 \% \text { milk }\end{array}$ & $10 \mathrm{~mL}$ & & \\
\hline & Table cream & $\begin{array}{l}\text { Neilson Dairy: } \\
18 \% \text { cream }\end{array}$ & $10 \mathrm{~mL}$ & & \\
\hline \multirow[t]{2}{*}{ Sweet treats } & Cranberry juice & $\begin{array}{l}\text { Ocean Spray: } \\
100 \% \text { cranberry juice blend }\end{array}$ & $10 \mathrm{~mL}$ & & \multirow{2}{*}{$\begin{array}{l}\text { Sweetness } \\
\text { Bitterness } \\
\text { Sourness }\end{array}$} \\
\hline & Diet cranberry juice & $\begin{array}{l}\text { Ocean Spray: } \\
\text { Diet cranberry juice }\end{array}$ & $10 \mathrm{~mL}$ & & \\
\hline \multirow[t]{3}{*}{ Textured foods } & Apple sauce & $\begin{array}{l}\text { Motts: } \\
\text { Original apple sauce }\end{array}$ & 2 tbsp & $\begin{array}{l}\text { Stored in and served directly from } \\
\text { refrigerator. } \\
\text { Plastic spoon provided. }\end{array}$ & $\begin{array}{l}\text { Sweetness } \\
\text { Sourness } \\
\text { Graininess }\end{array}$ \\
\hline & Extra firm tofu & $\begin{array}{l}\text { Sunrise: } \\
\text { Extra firm tofu }\end{array}$ & $1 / 2 \mathrm{~cm}^{2}$ & \multirow[t]{2}{*}{$\begin{array}{l}\text { Stored in and served directly from } \\
\text { refrigerator }\end{array}$} & \multirow[t]{2}{*}{$\begin{array}{l}\text { Saltiness } \\
\text { Firmness }\end{array}$} \\
\hline & Soft tofu & $\begin{array}{l}\text { Sunrise: } \\
\text { Soft tofu }\end{array}$ & $1 / 2 \mathrm{~cm}^{2}$ & & \\
\hline \multirow[t]{3}{*}{ Sweet treats } & Milk chocolate & $\begin{array}{l}\text { President's Choice: } \\
\text { Milk chocolate }\end{array}$ & $1 / 4$ square & \multirow{6}{*}{$\begin{array}{l}\text { Stored in airtight containers. } \\
\text { Covered with Saran wrap until } \\
\text { served }\end{array}$} & \multirow[t]{2}{*}{ Sweetness Bitterness } \\
\hline & Dark chocolate & $\begin{array}{l}\text { President's Choice: } \\
\text { Dark chocolate } 70 \% \text { cocoa }\end{array}$ & $1 / 4$ square & & \\
\hline & Junior mint & $\begin{array}{l}\text { Tootsie Roll Industries: } \\
\text { Junior mint }\end{array}$ & 1 candy & & $\begin{array}{l}\text { Sweetness Bitterness } \\
\text { Menthol coolness }\end{array}$ \\
\hline \multirow[t]{2}{*}{ Salty snacks } & Lightly salted chip & $\begin{array}{l}\text { Frita Lay's: } \\
\text { Lightly salted chip }\end{array}$ & 1 chip & & \multirow[t]{3}{*}{$\begin{array}{l}\text { Saltiness } \\
\text { Crispiness }\end{array}$} \\
\hline & Original chip & $\begin{array}{l}\text { Frita Lay's: } \\
\text { Original chip }\end{array}$ & 1 chip & & \\
\hline Textured foods & Crispbread & $\begin{array}{l}\text { Ryvita: } \\
\text { Multigrain crispbread }\end{array}$ & 1/4 cracker & & \\
\hline
\end{tabular}

as more bitter $(t(1,86)=89.3, p<0.0001)$ and less sweet $(t(1,86)=35.3, p<0.0001)$ than milk chocolate, as expected. Finally, salt-reduced chips were rated as less salty than original versions of the same brand $(t(1,86)=$ 8.2, $p=0.005)$.

TTs and TnTs sampled and rated the intensity of the dominant oral sensations elicited by 20 common food and beverage products. The average intensity score across food items within each orosensory grouping was calculated for each participant and a MANOVA performed on that data. There was a statistically significant difference in intensity ratings due to TTS: $F(9,33)=2.39, p=.03$; Wilk's $\Lambda=0.61$. TTs rated the bitter orosensory grouping as more intense than did TnTs $(F=2.59, p=0.01)$, but there were no significant differences between the phenotypes for other orosensory groups (Fig. 2). Figure 3 explores this result further and shows that all bitter-eliciting items were rated more intensely by TTs, although this trend was only significant for standard $(t(42)=3.37, p=0.01)$ and diet $(t(42)=2.84$, $p=0.04$ ) cranberry juices (Bonferroni corrections applied to observed $p$ values to compensate for multiple comparisons). No significant differences between TTs and TnTs 
Table 3 Composition of orosensory groups

\begin{tabular}{|c|c|c|}
\hline $\begin{array}{l}\text { Orosensory } \\
\text { group }\end{array}$ & $\begin{array}{l}\text { Cut-off value for inclusion } \\
\text { (average intensity rating }(\mathrm{mm}) \text { ) }\end{array}$ & Food item \\
\hline \multirow[t]{5}{*}{ Sweet } & \multirow[t]{5}{*}{40} & Milk chocolate \\
\hline & & Junior mint \\
\hline & & Cranberry juice \\
\hline & & Diet cranberry juice \\
\hline & & Apple sauce \\
\hline \multirow[t]{5}{*}{ Bitter } & \multirow[t]{5}{*}{32} & Asparagus \\
\hline & & Brussels sprout \\
\hline & & Dark chocolate \\
\hline & & Cranberry juice \\
\hline & & Diet cranberry juice \\
\hline \multirow[t]{2}{*}{ Sour } & \multirow[t]{2}{*}{40} & Cranberry juice \\
\hline & & Diet cranberry juice \\
\hline \multirow[t]{2}{*}{ Salty } & \multirow[t]{2}{*}{45} & Lay's original chip \\
\hline & & Lay's lightly salted chip \\
\hline Menthol cool & 60 & Junior mint \\
\hline \multirow[t]{5}{*}{ Creamy } & \multirow[t]{5}{*}{40} & Skim milk (0 \%) \\
\hline & & Low-fat milk (1 \%) \\
\hline & & Reduced-fat milk (2 \%) \\
\hline & & Whole milk (3.25 \%) \\
\hline & & Table cream (18\%) \\
\hline \multirow[t]{3}{*}{ Crispy } & \multirow[t]{3}{*}{60} & Lay's original chip \\
\hline & & Lay's lightly salted chip \\
\hline & & Ryvita crispbread \\
\hline \multirow[t]{2}{*}{ Firm } & \multirow[t]{2}{*}{45} & Soft tofu \\
\hline & & Extra firm tofu \\
\hline Grainy & 40 & Apple sauce \\
\hline
\end{tabular}

were found in intensity ratings for other food items nor were there any gender or gender $\times$ TTS effects.

\section{Liking}

TTs and TnTs also rated their overall liking of the 20 common food and beverage products. The average liking score across food items within each orosensory grouping was calculated for each participant and a MANOVA performed on that data. The results approached significance for TTS: $F(8,34)=1.87, p=.099$; Wilk's $\Lambda=0.70$. TTs gave significantly higher overall liking scores for the grainy orosensory group $(F(42)=3.61, p=0.001)$ (Fig. 4), but there were no differences for the other eight orosensory groups. Similarly, no differences were observed between TTs and TnTs in overall liking ratings for individual food products, except apple sauce, and there were no significant gender or gender $\times$ TTS effects.

We were also curious to further assess the relationship between reported and sampled food liking, given the use of the former in much consumer and population-based research, and the proposition that reported liking may be a more accurate proxy for actual consumption than traditional measures of dietary intake [2, 19]. Table 4 (Pearson's $r$ ) shows that the associations between selfreported and sampled liking are moderately, positively and significantly correlated for 15 of the 18 items.

\section{Discussion}

\section{Orosensation}

While there was an overall effect of TTS, a significantly more limited range of food items varied with the phenotype than we expected, given the heightened intensity experienced by TTs for a wide range of orosensations reported in simple aqueous solutions $[8,9,11,12]$, wine [14] and beer [15]. While it is possible the analyses were underpowered due to the sample size, it is noteworthy that this enhanced acuity has only been demonstrated robustly to date in solutions and not with solid or semisolid matrices, perhaps indicating that wider palate stimulation is necessary to recruit sufficient receptors to confer the greater responsiveness of TTs. Such a 'threshold' might be more readily achieved with solutions, with respect to both the area within the oral cavity stimulated and access to the receptors themselves. At this stage, it is not clear whether those receptors would be associated with trigeminal fibres (as postulated by the 'cross-wiring' theory advanced in Yang et al. [9]) and/or taste fibres.

An alternative and partial explanation for our limited findings with respect to thermal-taster acuity evokes the cognitive demands of simultaneously rating multiple orosensations in a complex sensory system such as food. This is a more challenging task than scoring the intensity of one attribute elicited by a single tastant, as has characterized earlier work using aqueous solutions or mouth swabs. More thorough training might have enhanced performance in our study by reducing the cognitive demands on participants, and allowed for greater differentiation in responses between TTs and TnTs. However, as indicated earlier, participants appear to be using the gVAS scales appropriately to discriminate between food types and orosensations. The greater responsiveness of TTs seen here for bitter-eliciting foods is consistent with the findings or trends reported in other studies for quinine sulphate [8, 11], 6-n-propylthiouracil [11], caffeine [9], wine [14] and beer [15].

\section{Liking and other considerations}

Participants rated their overall liking of the 20 food and beverage products and did so in a manner that suggested they were using the gDOL scale appropriately. For instance, they gave higher ratings to salty snacks and sweets treats and displayed greater disliking of vegetables, as expected (data not shown). We hypothesized 


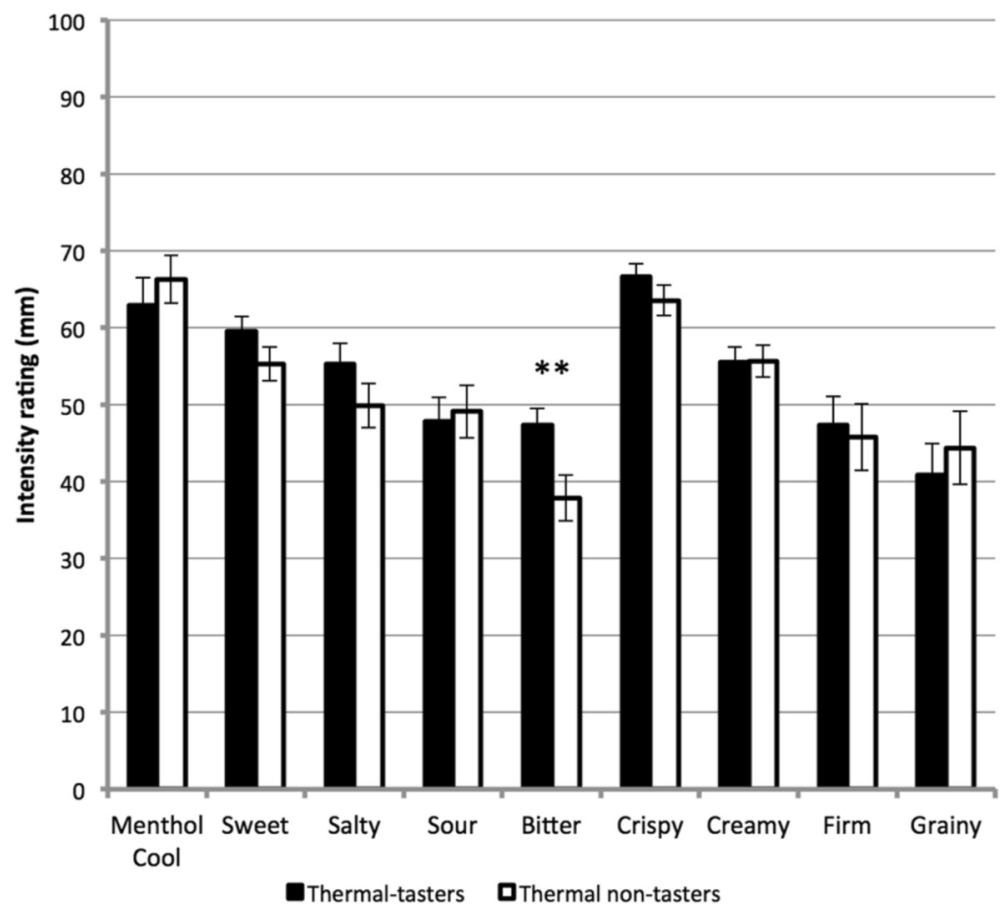

Fig. 2 Thermal taster status and intensity ratings for orosensory groups. ${ }^{* *} p<0.01$. Error bars indicate standard error

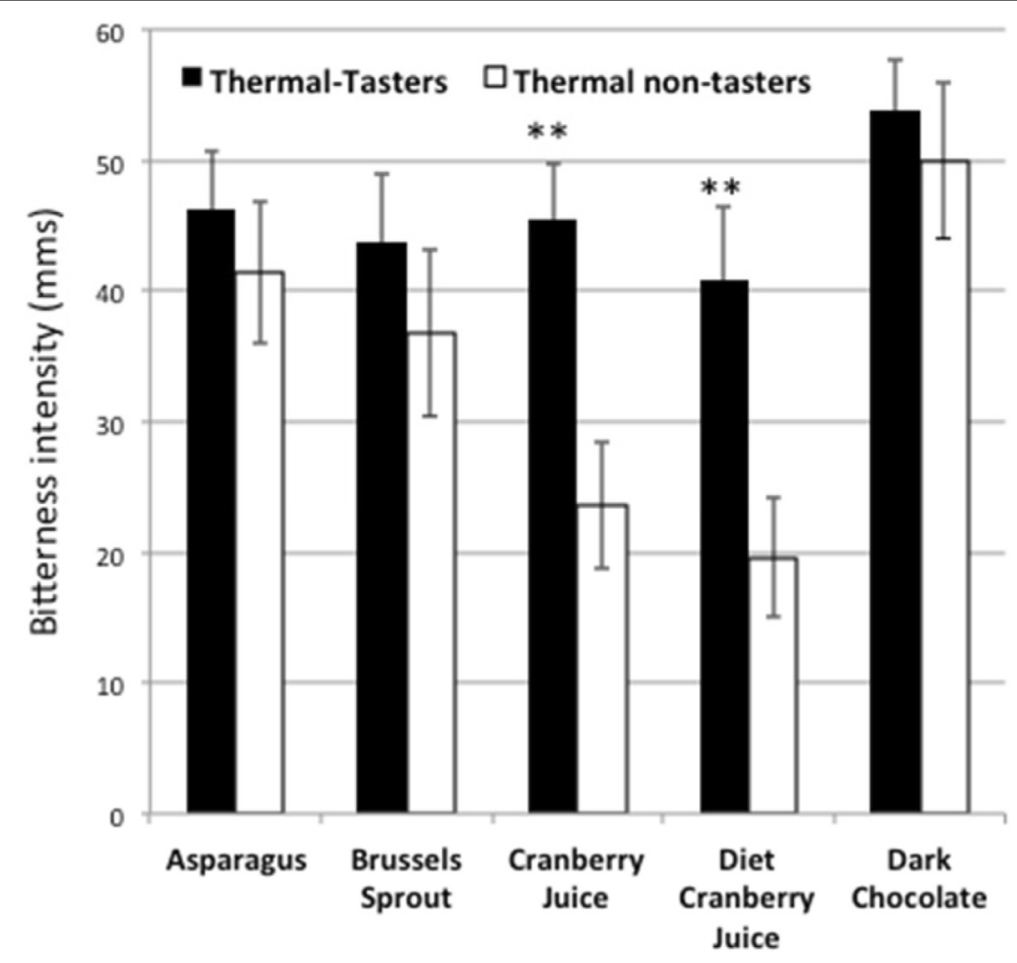

Fig. 3 Intensity ratings of bitter foods for thermal tasters and non-tasters. ${ }^{* *} p<0.01$ 


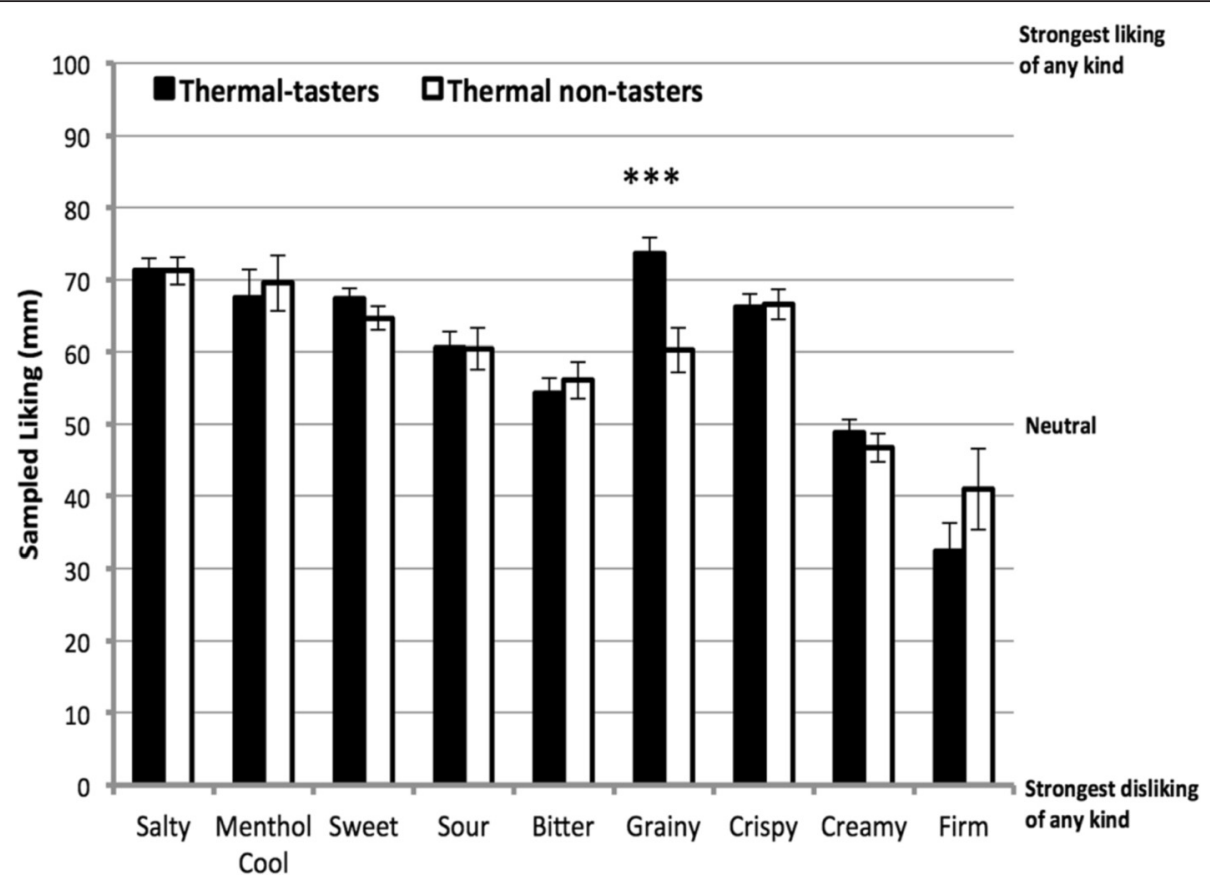

Fig. 4 Thermal taster status and overall liking ratings for orosensory groups. ${ }^{* *} p<0.001$. Error bars indicate standard error

Table 4 Association between self-rated liking and sampled liking of food and beverage products

\begin{tabular}{llll}
\hline Food products & Number & $r$ value & $p$ value \\
\hline $0 \%$ milk & 41 & 0.504 & 0.001 \\
$1 \%$ milk & 41 & 0.505 & 0.001 \\
$2 \%$ milk & 43 & 0.417 & 0.005 \\
$3.25 \%$ milk & 40 & 0.420 & 0.007 \\
$18 \%$ cream & 40 & 0.465 & 0.003 \\
Lay's lightly salted chip & 42 & 0.239 & 0.128 \\
Lay's original chip & 44 & 0.350 & 0.020 \\
Dark chocolate & 42 & 0.554 & 0.0001 \\
Milk chocolate & 44 & 0.482 & 0.001 \\
Junior mint & 42 & 0.584 & $<0.0001$ \\
Cranberry juice & 30 & 0.488 & 0.006 \\
Diet cranberry juice & 15 & 0.198 & 0.198 \\
Asparagus & 34 & 0.456 & 0.007 \\
Broccoli & 41 & 0.600 & $<0.0001$ \\
Brussels sprout & 30 & 0.509 & 0.004 \\
Sweet peas & 40 & 0.450 & 0.004 \\
Soft tofu & 36 & 0.612 & $<0.0001$ \\
Apple sauce & 43 & 0.239 & 0.123 \\
\hline Self-rat liking & & &
\end{tabular}

Self-rated liking data was not obtained for extra firm tofu or Ryvita crispbread that differences in the orosensations experienced between TTs and TnTs would be reflected in different liking scores. However, only one orosensory grouping of food differed between phenotypes, grainy, which must be viewed as a limited finding as only one food item comprised this group.

Although TTs tended to rate bitter foods more intensely, this did not translate into differences in liking of those foods. However, consumer research on food products typically involves a minimum of 100-150 participants when testing hypotheses on liking and preference; we acknowledge we are underpowered to robustly assess liking differences between taste phenotypes in this study, and it was a secondary objective. Additionally, multiple experiential, psychosocial and biological factors not examined here are known to influence food liking and consumption. Designing studies large enough to incorporate these factors and recruiting sufficient numbers of participants is a challenge in thermal tasting research, in part due to the length of time required to accurately determine TTS. Further work is encouraged into adapting the thermal-taste-eliciting apparatus and procedures to be more mobile, thus facilitating field-based studies. Amongst other benefits, this would allow for our bitterness finding to be examined with respect to diet-disease linkage; the bitterants in the products assessed here are phytochemicals with documented health-promoting properties, and include phenolics and isothiocyanates [20].

The close agreement between self-rated and sampled liking for the substantial majority of food items assessed 
adds some support to the argument that self-rated liking may be a valuable proxy for estimating food intake [19], at least for population-based studies. It is certainly less time-consuming and resource-intensive than many traditional measures. The lack of association for diet cranberry juice likely reflects the relative lack of familiarity with the product (only 15 participants rated this item), and with apple sauce, it may be due to a context effect: apple sauce is seldom consumed on its own, as was the case here. Indeed, it could be argued that the correlations for all items were not as high as expected due to the absence of moderators in the lab setting that are normally encountered with 'everyday' food consumption, including social and environmental cues (e.g., ambience of surroundings) and concurrent food items.

\section{Conclusions}

As a relatively poorly described but potentially important source of difference between individuals in orosensation and consumption behaviours, we investigated whether the greater responsiveness to orosensations previously reported for TTs from simple aqueous solutions and some beverages extends to sampled foods. Our findings showed that only food items that are predominantly bitter-eliciting differ with thermal tasting phenotype; thermal tasters tended to rate them as more bitter than did TnTs. Further research is encouraged to examine the possibility of thermal taster sub-types: differentiation of thermal tasters and supra-threshold responsiveness based on the specific phantom sensation elicited during lingual thermal stimulation. Self-reported liking of food items tended to associate strongly with sampled liking of the same products, providing some support for the utility of the former as a proxy for consumption in population-based studies.

\section{Acknowledgements}

Lynda Van Zuiden, Hannah Pickering, Jamie-Lee Robb, Dr. Glenn Tattersall and Dr. Andreea Botezatu (Brock University) are thanked for their technical, advisory and editorial support. Finally, we thank all participants who gave generously of their time to take part in this study.

\section{Funding}

We are grateful for the financial support of the Natural Sciences and Engineering Research Council of Canada through a Discovery grant to GP.

\section{Availability of data and materials}

The data supporting the conclusions of this article will be available in the Brock University digital repository (http://dr.library.brocku.ca/handle/10464/4).

\section{Authors' contributions}

SL and NG collected the data. GP conceived the study and acquired the funding. All authors participated in the data analysis and manuscript preparation. All authors read and approved the final manuscript.

\section{Ethics approval and consent to participate}

Ethics approval was obtained for this study through the Brock University Research Ethics Board (REB File 10-193). Participants consented to participation.

\section{Author details}

'Department of Biological Sciences, Brock University, St. Catharines, Ontario L2S 3A1, Canada. 'Department of Psychology, Brock University, St. Catharines, Ontario L2S 3A1, Canada. ${ }^{3} \mathrm{Cool}$ Climate Oenology and Viticulture Institute, Brock University, St. Catharines, Ontario L2S 3A1, Canada. ${ }^{4}$ Charles Sturt University, Locked Bag 588, Wagga Wagga, NSW 2678, Australia. ${ }^{5}$ University of the Sunshine Coast, Sippy Downs, Queensland 4556, Australia. ${ }^{6}$ Food Processing Development Centre, Food and Bio Processing Division, Alberta Agriculture and Forestry, Leduc, AB T9E 7C5, Canada.

Received: 5 May 2016 Accepted: 18 August 2016

Published online: 24 August 2016

\section{References}

1. Drewnowski A. Taste preferences and food intake. Annu Rev Nutr. 1997;17:237-53.

2. Duffy VB. Variation in oral sensation: implications for diet and health. Curr Opin Gastroenterol. 2007;23:171-7.

3. Tepper BJ. Nutritional implications of genetic taste variation: the role of PROP sensitivity and other taste phenotypes. Annu Rev Nutr. 2008;28:367-88.

4. Pickering GJ, Cullen CW. The influence of taste sensitivity and adventurousness on generation Y's liking scores for sparkling wine. In Proceedings of the Fourth International Conference of the Academy of Wine Business Research. Siena, Italy; 2008. CD, not paginated.

5. Garcia-Bailo B, Toguri C, Eny KM, EI-Sohemy A. Genetic variation in taste and its influence on food selection. Integr J Biol. 2009;13:69-80.

6. Hayes JE, Keast RSJ. Two decades of supertasting: where do we stand? Physiol Behav. 2011;104:1072-4.

7. Cruz A, Green BG. Thermal stimulation of taste. Nature. 2000;403:889-92.

8. Bajec MR, Pickering GJ. Thermal taste, PROP responsiveness and perception of oral sensations. Physiol Behav. 2008;95:581-90.

9. Yang Q, Hollywood T, Hort J. Phenotypic variation in oronasal perception and the relative effects of PROP and thermal taster status. Food Qual Pref. 2014;38:83-91.

10. Talavera K, Yasumatu K, Voets T, Droogmans G, Shigemura N, Ninomiya Y, Margolskee RF, Nilius B. Heat activation of TRPM5 underlies thermal sensitivity of sweet taste. Nature. 2005;438:1022-5.

11. Green $B G$, George P. Thermal taste predicts higher responsiveness to chemical taste and flavour. Chem Senses. 2004;29:617-28.

12. Bajec MR, Pickering GJ, Decourville N. Influence of stimulus temperature on orosensory perception and variation with taste phenotype. Chemosens Percept. 2012;5:243-65.

13. Pickering GJ, Kvas R. Thermal tasting and difference thresholds for prototypical tastes in wine. Chemosens Percept. 2016;9(1):37-46.

14. Pickering GJ, Moyes A, Bajec MR, Decourville N. Thermal taster status associates with oral sensations elicited by wine. Aust J Grape Wine Res. 2010;16:361-7.

15. Pickering GJ, Bartolini A, Bajec MR. Perception of beer flavour associates with thermal taster status. Int J Brew. 2010;116:239-44.

16. Bajec MR, Pickering GJ. Association of thermal taste and PROP responsiveness with food liking, neophobia, body mass index, and waist circumference. Food Qual Prefer. 2010;21:589-601.

17. Hayes JE, Grenga A, Swift RM. Possible gender effects in the relationship between alcohol intake and sweet food reward. Presented at: 8th Pangborn Sensory Symposium. Florence, Italy; 2009.

18. Pickering GJ, Klodnicki CE. Does liking and orosensation intensity elicited by sampled foods vary with thermal tasting? Chemosens Percept. 2016;9(2):47-55.

19 Duffy VB, Hayes JE, Sullivan BS, Faghri P. Surveying food and beverage liking: a tool for epidemiological studies to connect chemosensation with health outcomes. Ann N Y Acad Sci. 2009;1170:558-68.

20 Gaudette NJ, Pickering GJ. Modifying bitterness in functional food systems. Crit Rev Food Sci Nutr. 2013;53:464-81. 